\title{
Classificação de guerras: a problemática das (in)definições
}

\section{Classification of wars: the trouble with the (in)definitions}

Rev. Bra. Est. Def. v. 4, n 1, jan./jun. 2017, p. 45-58

DOI: $10.26792 /$ RBED.v4n 1.2017.65352

ISSN 2358-3932

\section{AUGUSTO CÉSAR DALL'AGNOL ARTHUR COELHO DORNELLES JR.}

\section{INTRODUÇÃO}

O presente ensaio ${ }^{1}$ tem como objetivo geral abordar as questões relativas à problemática em que estão envolvidos os conceitos de guerra interestatal. Tal esforço justifica-se, sobretudo, por conta de confusões conceituais no entendimento de que guerras locais e guerras limitadas são sinônimos. Infelizmente, o mesmo tipo de confusão ocorre com os conceitos de guerra total e guerra absoluta, frequentemente empregados de forma intercambiável.

Abaixo, procura-se desenvolver, ainda que de forma propedêutica, os elementos elencados para a diferenciação entre os tipos de guerra em questão. Entende-se que é de fundamental importância estabelecer critérios distintivos que permitam uma classificação apurada das guerras. Entende-se que tais critérios podem, eventualmente, representar uma contribuição ao debate acerca da tipologia das guerras. Assim, a primeira seção deste ensaio trata da diferenciação clausewitiziana entre guerras absolutas e guerras reais. A segunda, por sua vez, contrapõe os dois tipos identificados de guerras reais, a saber, as guerras totais e as guerras limitadas. Por fim, a

\footnotetext{
Augusto César Dall’Agnol - Mestrando do Programa de Pós-Graduação em Estudos Estratégicos Internacionais pela Universidade Federal do Rio Grande do Sul (UFRGS). Bacharel em Relações Internacionais pela Universidade Federal de Santa Maria (UFSM). Pós-graduando vinculado ao Grupo de Estudos em Capacidade Estatal, Segurança e Defesa (GECAP). Bolsista da Coordenação de Aperfeiçoamento de Pessoal de Nível Superior (CAPES).

Arthur Coelho Dornelles Jr. - Professor Adjunto do Departamento de Ciências Sociais da Universidade Federal de Santa Maria (UFSM). Doutor em Ciência Política pela Universidade Federal do Rio Grande do Sul (UFRGS), e Mestre em Relações Internacionais pela mesma instituição. Pesquisador efetivo do Grupo de Estudos em Capacidade Estatal, Segurança e Defesa (GECAP).
} 
terceira seção apresenta uma definição das guerras locais e das guerras centrais.

\section{GUERRAS ABSOLUTAS VS GUERRAS REAIS}

De imediato, destaca-se que a guerra absoluta é aquela que existe no plano ideal. ${ }^{2}$ Daí decorre a máxima de Clausewitz (2003, 75) de que "a guerra é um ato de força para obrigar o nosso inimigo a fazer a nossa vontade”. Convém assinalar, desde já, que a guerra absoluta decorre de três princípios propostos por Clausewitz (2003). O primeiro princípio é o da ação e reação, isso é, "a guerra é um ato de força e não existe qualquer limite lógico para que o emprego desta força seja limitado. Cada lado obriga, portanto, o seu oponente a fazer o mesmo que ele”. O segundo princípio é de que a guerra envolve duas ou mais forças vivas e, neste sentido, "enquanto eu não tiver derrotado o meu oponente, estarei fadado a temer que ele vá me derrotar". O terceiro princípio é de que a guerra absoluta pressupõe o emprego máximo da força e, desta forma, para sobrepujar o inimigo, o ator deve combinar a totalidade de meios a sua disposição e a força da sua determinação” (Clausewitz 2003, 77-78). Em síntese, a guerra absoluta clausewitziana seria a própria guerra entregue a sua lógica interna.

A guerra real, por sua vez, ainda associada às contribuições de Clausewitz (2003), reflete os limites da guerra absoluta. Isto é, o mundo real apresenta tendência à moderação. Assim, três lógicas fundamentais levam a essa tendência, a saber: i) a dispersão das forças; ii) a probabilidade; e iii) o ato político. Quanto à dispersão de forças, cabe ressaltar que a guerra nunca é um ato isolado, isto é "a guerra nunca irrompe de uma maneira totalmente inesperada, nem pode alastrar-se instantaneamente” (Clausewitz 2003, 79). Além disso, a guerra não consiste em um único golpe brusco e "a decisão da guerra consiste em diversos atos sucessivos, então, cada um deles, vistos dentro do contexto, proporcionará uma maneira de avaliar os que virão depois" e, com isso, a totalidade dos seus recursos não seria, portanto, mobilizada imediatamente (Clausewitz, 2003, 80).

No que diz respeito à probabilidade e ao acaso, Clausewitz (2003, 88) aponta que "a natureza objetiva da guerra a torna uma questão de avaliar probabilidades”. Assim, nenhuma outra atividade humana está tão ligada ao acaso e à adivinhação e, com isso, a sorte vem a desempenhar um importante papel na guerra. Isso se reflete na ideia de Clausewitz $(2003,88)$ de que "cada lado, utilizando as leis da probabilidade, faz uma avaliação de qual será o provável rumo do seu oponente e age de acordo com ele”. Por fim, o ato político diz respeito à ideia de que "a guerra é meramente a con- 
tinuação da política por outros meios" e, diante disso, "o propósito político é a meta, a guerra é o meio de atingi-lo, e o meio nunca deve ser analisado isoladamente do seu propósito" (Clausewitz 2003, 91). Em outras palavras, a política está sempre presente na guerra, de modo a modular constantemente o emprego dos meios militares conforme as necessidades impostas pelos objetivos políticos.

Nesse sentido, tendo em vista que a guerra absoluta é uma abstração, uma construção mental, faz-se necessário destacar que as guerras reais podem ser divididas entre guerras totais e guerras limitadas, que serão exploradas a seguir. Diante disso, cabe assinalar, desde já, que a guerra total não corresponde à aplicação pura e simples do conceito de guerra absoluta encontrada em Clausewitz e que, ainda que o prussiano tenha se inspirado nas guerras napoleônicas, essas eram uma aproximação do conceito absoluto, e não o próprio.

\section{GUERRAS REAIS: GUERRA TOTAL VS GUERRA LIMITADA}

A guerra total é aqui interpretada como a disseminação do impacto da guerra e da mobilização de toda a sociedade para o combate entre Estados. Neste sentido, Ludendorff (1941), Daudet (1918) e Guiomar (2004) entendem que o aparecimento da guerra total se dá primeiramente com as guerras napoleônicas, ainda que ela se consolide totalmente apenas com as grandes guerras do século XX. Além disso, os autores veem na $1^{\text {a }}$ Guerra Mundial o surgimento efetivo da guerra total devido, sobretudo, à fusão entre as Forças Armadas e a população. Bell et al. (2011, 158) apontam, nesse sentido, que "a combinação dos sistemas de recrutamento, característicos do advento da democracia e da conscrição universal”, além da "evolução dos sistemas de armas inovadoras - com base inicial em uma mobilização industrial e, depois, econômica - e de uma burocracia de guerra, traz um novo tipo de guerra" sem precedentes nos anais da civilização.

Outro aspecto peculiar da guerra total, trazido por Guiomar (2004, 19-20), é que se trata de uma guerra em que o deflagrador do conflito não pode interrompê-la, o que permite uma escalada vertical. ${ }^{3}$ Daudet (1918, 8 ), por exemplo, define a guerra total como a "extensão da luta nas fases mais agudas e crônicas aos domínios político, econômico, comercial, industrial, intelectual, jurídico e financeiro", isto é, a guerra total não consiste apenas em um combate clássico entre forças militares, mas um conflito entre sociedades nacionais. Por fim, a guerra total faz com que "o centro de gravidade de um conflito deixe de ser as Forças Armadas de uma dada nação, para passar a ser efetivamente a sua população e a sua base econômica de sustentação” (Duarte, 2005, 49). 
As guerras limitadas são aqui tratadas como aquelas que transcorrem em contextos em que, diferentemente das guerras totais, a motivação popular é mínima ou moderada, além de que o objetivo político destas são consideradas de menor relevância pelos Estados. Em segundo lugar, a mobilização de recursos para a guerra é limitada. Assim, adotando uma perspectiva clausewitziana, Duarte (2012, 70) assinala que se os incentivos da guerra têm o mesmo valor para ambas as partes, essas procurarão resolver suas disputas políticas em procura de um equilíbrio equiparável. Isso é, em uma guerra limitada "o inimigo é compelido a uma barganha diplomática após os custos de resistência armada e de perdas pelos enfrentamentos ultrapassarem um determinado limiar" (Duarte 2012, 70). Por outro lado, convém salientar que se os incentivos de um lado significam perdas para o outro, o equilíbrio demorará mais para ser alcançado, e "aquele lado em melhores condições de se manter por mais tempo em enfrentamentos conseguirá a melhor barganha sobre aquele que urge mais pela paz" (Duarte 2012, 70).

Em síntese, Duarte $(2012,70)$ sinaliza que o êxito em guerras limitadas envolve a combinação de operações ofensivas e defensivas. Isto é, as operações ofensivas dizem respeito "a tomada de objetos considerados de valor pelo oponente e a destruição ocasional de suas forças combatentes de maneira a provocar danos de sua utilidade em termos de barganha política sobre nossos objetos de valor”. O autor aponta, ainda, que as operações defensivas visam à "defesa de objetos de valor conquistados ao oponente e a defesa de forças combatentes para sua economia e manutenção de um equilíbrio de forças sempre vantajoso”. Dessa maneira, é possível ter o controle das operações militares no teatro de operações de maneira que qualquer iniciativa do oponente seja relativamente mais custosa. A expectativa teórica é que esta atuação defensiva final, que permite a consolidação de um acordo de paz ou cessar-fogo vantajoso, seja realizada mediante a desistência do oponente de seguir lutando por aceitação de proposta de acordo, que pode ou não envolver a troca de recursos de valor, a depender da momentânea distribuição de forças entre os contendores no encerramento do conflito. Vasquez $(1986,321)$ entende que as guerras de construção de Estado, como no caso italiano e alemão, tendem a ser limitadas por terem objetivos altamente específicos envolvendo questões pontuais de controle de territórios fronteiriços. O Quadro 1, a seguir, sintetiza os elementos de diferenciação entre guerras absolutas e guerras reais, e entre guerras totais e guerras limitadas. 
QUADRO 1 - Síntese da distinção entre guerras.

\begin{tabular}{|c|c|c|c|}
\hline & \multirow{2}{*}{$\begin{array}{l}\text { GUERRA } \\
\text { ABSOLUTA }\end{array}$} & \multicolumn{2}{|c|}{ GUERRA REAL } \\
\hline & & Guerra total & Guerra limitada \\
\hline Objetivos & Militares & Políticos e militares & $\begin{array}{l}\text { Políticos (específicos e } \\
\text { pontuais) }\end{array}$ \\
\hline Meios & Militares & Militares e diplomáticos & Militares e diplomáticos \\
\hline Fins & $\begin{array}{l}\text { Destruição } \\
\text { completa do } \\
\text { adversário }\end{array}$ & $\begin{array}{l}\text { Extermínio ou rendição } \\
\text { incondicional, ou } \\
\text { capitulação do adversário }\end{array}$ & $\begin{array}{l}\text { Desarmamento do } \\
\text { adversário, ou conquista } \\
\text { de objetivos específicos }\end{array}$ \\
\hline $\begin{array}{l}\text { Mobilização de } \\
\text { forças }\end{array}$ & $\begin{array}{l}\text { Combinação da } \\
\text { totalidade de } \\
\text { meios. Não há } \\
\text { limite }\end{array}$ & $\begin{array}{l}\text { Embate entre sociedades } \\
\text { nacionais (forças } \\
\text { militares, recursos } \\
\text { econômicos, financeiros, } \\
\text { comerciais, intelectuais, } \\
\text { tecnológicos, políticos) }\end{array}$ & $\begin{array}{l}\text { Embate entre forças } \\
\text { militares (distinção } \\
\text { clara da tríade } \\
\text { clausewitziana - } \\
\text { sociedade, militares, } \\
\text { Estado), além de } \\
\text { motivação popular } \\
\text { mínima }\end{array}$ \\
\hline Escalada & $\begin{array}{l}\text { Pressupõe } \\
\text { uma escalada } \\
\text { vertical ainda } \\
\text { não existente }\end{array}$ & $\begin{array}{l}\text { Se houver grande } \\
\text { escalada vertical pode se } \\
\text { aproximar do que seria } \\
\text { uma guerra absoluta }\end{array}$ & $\begin{array}{l}\text { Se houver forte } \\
\text { escalada vertical pode } \\
\text { se transformar em uma } \\
\text { guerra total }\end{array}$ \\
\hline Exemplos & $\begin{array}{l}\text { Inexistente } \\
\text { (plano das } \\
\text { ideias) }\end{array}$ & $\begin{array}{l}1^{\mathrm{a}} \text { Guerra Mundial e } \\
2^{\mathrm{a}} \text { Guerra Mundial }\end{array}$ & $\begin{array}{l}\text { Guerra russo-japonesa, } \\
\text { Guerra da Crimeia e } \\
\text { Franco Prussiana }\end{array}$ \\
\hline
\end{tabular}

Fonte: Elaboração dos autores.

\section{GUERRA CENTRAL VS GUERRA LOCAL}

Cabe destacar, desde já, que a ideia trazida aqui de guerra local difere do conceito chinês de local war, ${ }^{4}$ amplamente utilizado nos estudos da área dos Estudos Estratégicos ou de Segurança Internacional. Assim, assume-se que as principais diferenças entre as guerras locais e as centrais se dão, sobretudo, em relação ao número e ao tipo de países envolvidos no conflito, além da diferenciação temporal e de abrangência geográfica. Martins $(2013,182)$ sintetiza a discussão entre a diferença entre as guerras locais e centrais ao argumentar que as duas guerras mundiais podem ser consideradas como "a soma de duas guerras locais que escalaram no âmbito vertical e horizontal, produzindo uma conflagração generalizada”. Entretanto, como a distinção da escalada vertical no presente trabalho encontra-se na diferenciação entre guerras limitadas e totais - e não na diferenciação entre guerras locais e centrais - utilizar-se-á o exemplo de Martins (2013) 
com a finalidade de demonstrar a incidência do número e tipo de Estados envolvidos no conflito. A ideia central proposta por Martins (2013, 182) é de que duas - ou mais - guerras locais podem se sobrepor e resultarem em uma guerra central. ${ }^{5}$

O primeiro, e mais importante, critério de distinção entre guerras locais e centrais diz respeito ao número e tipo dos atores envolvidos. Assim, entende-se que uma guerra central pressupõe, no mínimo, três grandes potências ${ }^{6}$ do sistema - ou a presença de duas superpotências - em conflito, enquanto uma guerra local permite a presença de duas grandes potências, ou uma superpotência e/ou outros Estados com menor peso relativo em termos de capacidades materiais.

O segundo ponto de diferenciação de guerras locais e centrais dá-se pela abrangência geográfica das guerras. Assim, guerras centrais caracterizam-se por conflagrações generalizadas que abrangem grandes áreas geográficas, isto é, há diversos focos e fronts na guerra. As guerras locais, por sua vez, compreendem guerras confinadas geograficamente, ou seja, aquelas em que, ou pela presença reduzida no número de Estados, ou pelos conflitos não tomarem grandes proporções, acabam restritos a uma área limitada.

O terceiro ponto de distinção entre as guerras locais e centrais são as suas durações em tempo. Entende-se que as guerras centrais têm propensão a se estender em duração - anos ou décadas -, sobretudo pelo fato da escalada horizontal, que será vista a seguir. Já as guerras locais tendem a ter menor duração - semanas ou meses - uma vez que, normalmente, são guerras com objetivos específicos e pontuais que não levam a uma escalada horizontal da guerra, podendo os países beligerantes contarem com os suprimentos e armamentos dos seus aliados. Convém, desde já, assinalar que guerra local não é sinônimo de guerra limitada. Ou seja, admite-se, aqui, a existência de quatro tipos de guerras na análise proposta, conforme sintetizado a seguir na Figura 1. Assim, o critério de duração de uma determinada guerra só é interessante para a diferenciação de guerras se utilizado em conjunto com os demais elementos de análise propostos. 


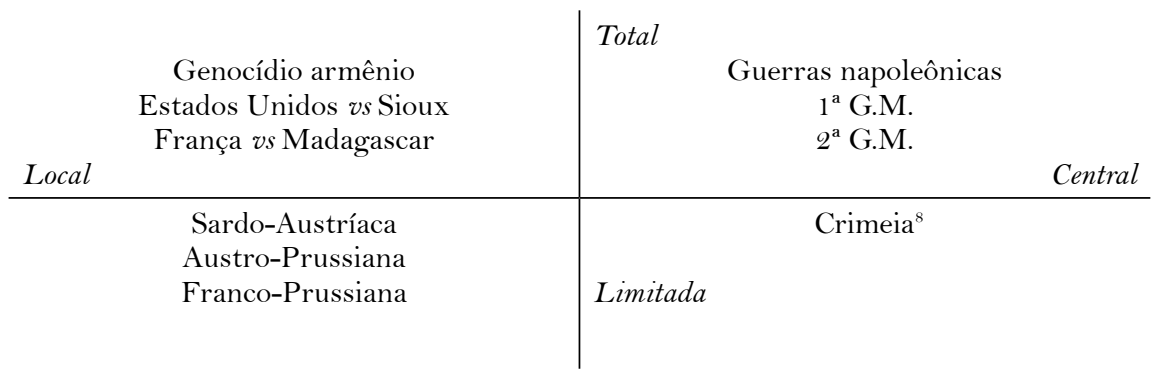

FIGURA 1. Binômios de guerras possíveis ${ }^{7}$

Fonte: Elaboração dos autores.

O quarto e último ponto de diferenciação das guerras locais e centrais versa acerca da escalada horizontal. Kahn $(1969,23)$ entende que a escalada horizontal diz respeito ao aumento da intensidade da guerra em decorrência da participação de novos beligerantes. Assim, cumpre destacar que, diferentemente do elemento utilizado para distinguir guerras totais e limitadas - escalada vertical - as guerras locais e centrais diferenciam-se quanto à escalada horizontal. Por exemplo, a $1^{a}$ Guerra Mundial, poderia ser descrita como o acúmulo da confrontação entre a Rússia e a Áustria-Hungria - que poderia ter resultado na $3^{\mathrm{a}}$ Guerra Balcânica - e do acirramento de ânimos entre Alemanha e França na disputa pelas regiões de Alsácia e Lorena. Ou seja, entende-se que o sistema de alianças, paradoxalmente construído para evitar a guerra, acaba permitindo a generalização de guerras locais até o ponto em que essas se transformem em guerras centrais - através da inserção de outras grandes potências nessas alianças (Martinez 1993; Martins 2013).

Neste sentido, para identificar em que quadrante (Figura 1) cada guerra se insere, sugere-se a mensuração dos elementos qualitativos inferidos a partir das guerras em análise. A mensuração desses elementos é definida como se segue. Os objetivos: $\mathrm{O}=$ políticos, $1=$ políticos $/$ militares e $2=$ militares. Os meios: $0=$ diplomáticos, $1=$ diplomáticos $/$ militares e $2=$ militares. Os fins: $\mathrm{O}=$ conquista dos objetivos políticos ou desarmamento do adversário, 1 = extermínio ou rendição incondicional/capitulação e $2=$ destruição completa do adversário. A mobilização de forças: $0=$ respeito à tríade clausewitziana, $1=$ desrespeito à tríade e $2=$ combinação da totalidade de meios. A escalada: $\mathrm{O}=$ ausência de escalada vertical, $1=$ presença de escalada vertical e 2 = escalada vertical absoluta. A quantidade e tipo de atores: $\mathrm{O}=$ até duas grandes potências, $1=$ duas grandes potências e outras potências médias e $\mathcal{2}=$ três ou mais do que três grandes potências/duas 
superpotências. A abrangência: $\mathrm{O}=$ confinada geograficamente no sistema, 1 = confinada geograficamente, mas mais do que um front e $2=$ grande abrangência geográfica. A duração: $0=$ semanas, $1=$ meses e $2=$ anos. A escalada: 0 = ausência de escalada horizontal, 1 = presença de escalada horizontal moderada e $2=$ grande escalada horizontal. Com isso, a partir do cálculo da média simples de cada binômio de guerra possível, pode-se inferir em que quadrante determinada guerra se insere - levando-se em consideração que o eixo horizontal e o eixo vertical variam de zero a dois.

O Quadro 3, a seguir, sintetiza a compreensão dos elementos expostos anteriormente, que permitem a diferenciação de uma guerra central de uma guerra local no presente trabalho.

\section{QUADRO 2 - Guerra Central vs Guerra Local}

\begin{tabular}{|l|l|l|}
\hline & Guerra central & Guerra local \\
\hline $\begin{array}{l}\text { Quantidade e } \\
\text { tipo de atores }\end{array}$ & $\begin{array}{l}\text { Normalmente complexa } \\
\text { (presença de três ou mais } \\
\text { grandes potências), mas pode } \\
\text { ser diádica (presença de duas } \\
\text { superpotências) }\end{array}$ & $\begin{array}{l}\text { Normalmente diádica (presença de } \\
\text { no máximo duas grandes potências, } \\
\text { e/ou participação de médias } \\
\text { potências e outros Estados) }\end{array}$ \\
\hline Abrangência & $\begin{array}{l}\text { Grande abrangência geográfica } \\
\text { no sistema }\end{array}$ & $\begin{array}{l}\text { Confinada geograficamente no } \\
\text { sistema }\end{array}$ \\
\hline Duração & Alta ou média (anos ou décadas) & Curta (semanas ou meses) \\
\hline Escalada & $\begin{array}{l}\text { Presença de escalada horizontal. } \\
\text { Quanto maior a escalada } \\
\text { horizontal, mais sistêmica será } \\
\text { a guerra }\end{array}$ & $\begin{array}{l}\text { Ausência de escalada horizontal. Se } \\
\text { houver escalada horizontal, então } \\
\text { pode se transformar em uma guerra } \\
\text { central }\end{array}$ \\
\hline
\end{tabular}

Fonte: Elaboração dos autores.

Por fim, para além da mera diferenciação entre os tipos de guerras mencionados, entende-se pertinente a operacionalização de tais tipologias. Neste sentido, identifica-se, aqui, um elemento externo - que vincula o grau de mudança que cada guerra no sistema em análise - ao binômio guerras locais-centrais e limitadas-totais: o elemento magnitude. Para tanto, destaca-se que sistemas são compostos por quatro níveis principais estrutura, interação, unidades e externo - e nove elementos de análise que estão continuamente sujeitos a mudanças (Castellano da Silva 2015). Assim, a estrutura envolve i) o fundamento estrutural, que diz respeito à organização e à natureza (tipo) de unidades; ii) a polaridade, que trata da distribuição de poder entre unidades; iii) a ordem, que se refere às regras políticas, econômicas, sociais e securitárias; e iv) as fronteiras, isto é, os li- 
mites estabelecidos por meio das interações. Quanto ao nível da interação, há que se destacar: i) a polarização, ou seja, a consolidação de alianças e rivalidades entre unidades em blocos estáveis; e ii) o padrão cooperação-conflito, que trata da interação entre as unidades (ações e reações). O nível das unidades diz respeito à: i) política externa, isto é, o posicionamento externo e comportamento das unidades; e ii) a característica das unidades, que representa os atributos e composição das unidades. Por fim, o fator externo diz respeito à penetração extrarregional de potências externas ao sistema em questão.

Assim, a partir de inferências qualitativas, busca-se mensurar os impactos de diferentes guerras na mudança do sistema em valores quantitativos expressos em uma escala que varia de zero e cinco. ${ }^{8}$ Neste sentido, entende-se que a análise da média simples obtida entre o tipo de guerra e a média simples do grau de mudança (magnitude) - que varia de zero a cinco - de determinada guerra permite um potencial analítico para o estudo de guerras e mudanças sistêmicas.

\section{CONSIDERAÇÕES FINAIS}

Por fim, algumas considerações preliminares podem ser feitas acerca das diferenciações das guerras aqui propostas. Primeiramente, destaca-se que: i) guerras locais e limitadas não são sinônimas, assim como guerras totais e centrais também não o são; ii) guerras locais contrapõem-se a guerras centrais, enquanto guerras totais contrapõem-se às guerras limitadas. Dessa forma, entende-se que guerras locais podem evoluir para guerras centrais, e vice-versa, enquanto guerras limitadas podem se transformar em guerras totais. Outro fato pertinente que merece ser destacado diz respeito aos critérios que permitem a diferenciação entre as guerras. As guerras limitadas e totais diferenciam-se nos objetivos, meios, fins, mobilização de forças e escalada vertical. As guerras locais e centrais, por sua vez, distinguem-se na medida em que diferem em relação ao tipo e número de atores envolvidos, abrangência geográfica, duração, escalada horizontal e magnitude.

Nesse sentido, diante da propagação das diversas definições de guerras, entende-se que é de fundamental importância evitar incompreensões em relação ao tipo de guerra a qual se busca referir. Assim, o presente ensaio traz, ainda que de forma inicial, uma proposta para a distinção entre guerras locais, centrais, totais e limitadas. Acredita-se que a classificação das guerras é pertinente, na medida em que auxilia a comparação entre estas. Além disso, as classificações propostas apresentam critérios minimamente objetivos para que se possa distinguir as guerras através de inferências 
qualitativas ou quantitativas. Não se pretende, entretanto, esgotar o assunto neste ensaio. Questões pertinentes e que contribuiriam para o avanço nas classificações e definições de guerra versariam acerca, por exemplo, dos diferentes impactos causados por tais guerras nos elementos constitutivos do sistema regional ou internacional, dos fatores que limitam, ou não, tanto a escalada vertical quando horizontal nas guerras do século XXI e, por fim, dos diálogos e pontes com os conceitos de small war e people's war utilizados pela China.

\section{REFERÊNCIAS}

Bell, D., Crépin, A., Drevillon, H., Forcade, O., Gainot, B. 2011. Autour de la guerre totale. Annales historiques de la révolution française, 366, 153-170.

Blasko, D. J. 2009. Military parades demonstrate chinese concept of deterrence. China Brief Volume, 9, 8, 7-10.

Brodie, B. 2003. Um guia para a leitura de Da Guerra. In: Clausewitz, von. 2003. Da Guerra. São Paulo: Martins Fontes e Brasília: UnB.

Castellano da Silva, I. 2015. Política externa na África Austral: causas das mudanças nos padrões de cooperação-conflito (1975-2010). Tese de Doutorado, PPG de Estudos Estratégicos Internacionais, Universidade Federal do Rio Grande do Sul, Porto Alegre.

Clausewitz, K. von. 2003. Da Guerra. São Paulo: Martins Fontes e Brasília: UnB.

Daudet, L. 1918. La Guerre Totale. Paris: Nouvelle Librairie Nationale.

Duarte, A. P. 2005. A visão de guerra total no pensamento militar. Nação e Defesa. Lisboa: Instituto da Defesa Nacional, n. 112, 33-50.

Duarte, É. 2012. Conduta da guerra na era digital e suas implicações para o Brasil: uma análise de conceitos, política e práticas de defesa. Rio de Janeiro: IPEA.

Guiomar, J.-Y. 2004. l'invention de la Guerre Totale: XVIII-XX siècle. Paris: Félin.

Kahn, H. 1969. A escalada. Rio de Janeiro: Bloch.

Ludendorff, E. 1941. A Guerra Total. Rio de Janeiro: Editorial Inquérito.

Martinez, R. 1993. An archetype for european security. Miami: University of Miami. 
Martins, J. M. Q. 2013. Considerações finais: recomposição hegemônica e as relações internacionais do Brasil. In: Martins, J. M. Q. (Org.). Relações Internacionais Contemporâneas 2012/02: estudos de caso em política externa e de segurança. 2013. Porto Alegre: ISAPE.

Martins, J. M. 2008. Digitalização e Guerra Local como fatores do equilíbrio internacional. Tese de Doutorado, PPG de Ciência Política, Universidade Federal do Rio Grande do Sul. Porto Alegre.

Midlarsky, M. I. 1984. Preventing systemic war: crisis decision-making amidst a structure of conflict relationships. Journal of Conflict Resolution, 28, 4, 563-584.

Pillsburry, M. 1998. Chinese views of future warfare. Washington: NDU Press.

Vasquez, J. A. 1986. Capability, Types of War, Peace. The Western Political Quarterly, 39, 2, 313-327. 


\section{NOTAS}

1. Os autores agradecem aos pareceristas anônimos e ao prof. Dr. Igor Castellano da Silva - Departamento de Economia e Relações Internacionais da Universidade Federal de Santa Maria (UFSM) - pela leitura e pelos comentários ao texto. Os eventuais erros contidos no ensaio são de inteira responsabilidade dos autores.

2. Como assinala Brodie (2003, 762), Clausewitz emprega no livro "Da Guerra" imagens de palavras tornadas moda pelos grandes filósofos alemães, como Kant e Hegel, que haviam revivido intensamente a velha escola metafísica que leva o nome de idealismo. Diante disso, "a guerra é simplesmente uma outra forma de ser, que como qualquer outra advém de um padrão, ou de uma "ideia” essencial, na qual possui a sua verdadeira realidade”. Assim, o autor aponta que, para compreender corretamente a guerra, devemos vê-la, primeiramente, em sua forma "absoluta" ou "ideal", o que Clausewitz chama de "conceito puro da guerra".

3. Kahn $(1969,23)$ sinaliza que uma escalada vertical corresponde ao aumento da intensidade da guerra pelo emprego de mais tropas ou, então, de armamentos de maior poder destrutivo.

4. A ideia chinesa de local war pode ser encontrada em Blasko (2009) e em Pillsburry (1998). Entretanto, os chineses se referem à escala da guerra, em detrimento da sua localização ou de quantos e que tipo de países estão em conflito. Isso decorre do significado de local em chinês $(j u b u$ ), que significa tanto regional, parcial, seccional ou local ao mesmo tempo (Pillsburry, 1998, xxvii).

5. O presente ensaio não tem como objetivo compreender as razões pelas quais surge uma guerra central. Algumas hipóteses são encontradas em Midlarsky (1984), que argumenta que elas começam com o aumento do número de Estados-nação e com a interdependência dos conflitos que podem se sobrepor, e em Martinez (1993), que sustenta o argumento de que surgem em decorrência do efeito contagioso das alianças.

6. Para o sistema regional europeu do século XIX e XX, Martinez (1993, 8), com base no Correlates of War (COW) sinaliza que as grandes potências eram: França de 1815-1940 e 1945-1980, Inglaterra de 1815-1980, Rússia/ URSS de 1815-1917 e 1921-1980, Sardenha/Itália de 1860-1943, Áustria/ Áustria-Hungria de 1815-1818 e, por fim, Prússia/Alemanha de 1815-1918 e 1925-1945. Cabe destacar que o estudo do autor avança até os anos 1980, não permanecendo atualizado desde então as grandes potências europeias.

7. Assume-se, aqui, a existência de diferenças mais amplas e fluidas entre as guerras. Isto é, não se entende que guerras centrais não tenham caráter de guerras locais - e vice-versa - ou que guerras totais não tenham aspectos que se aproximem de guerras limitadas, enquanto o inverso também é verdadeiro. Assim, não se pretende enquadrar as guerras categorias completamente antagônicas, permitindo uma maior fluidez para a classificação dessas. 
8. Considera-se, aqui, a Guerra da Crimeia (1853-1856) uma guerra central em relação ao sistema regional europeu do século XIX.

9. Zero (ausência de mudança), um (mudança muito baixa), dois (mudança baixa), três (mudança média), quatro (mudança alta) e, finalmente, cinco (mudança muito alta). 


\section{CLASSIFICAÇÃO DE GUERRAS: A PROBLEMÁTICA DAS (IN)DEFINIÇÕES}

\section{RESUMO}

O presente ensaio tem como objetivo geral abordar as questões relativas à problemática em que estão envolvidas as diferentes conceituações de guerra interestatal. Para tanto, propõe estabelecer critérios minimamente objetivos para que se possa distinguir os tipos de guerras através de inferências qualitativas ou quantitativas.

Palavras-chave: Guerras Locais; Guerras Centrais; Guerras Limitadas; Guerras Totais.

\section{ABSTRACT}

The main essay aims to present issues related to the problematic in which the use of concepts of wars are envolved. It propose, thus, to establish minimally defined criterea so that we can distinguish wars through qualitative or quantitative inferences.

Keywords: Local Wars; Central Wars; Limited Wars; Total Wars. 